\title{
Experimental and Numerical Investigation of
}

\section{Adsorption/Desorption in Packed Sorption Beds}

\section{under Ideal and Non-Ideal Flows}

\author{
H. Mohamadinejad \\ Boeing Aerospace Company \\ Huntsville, AL
}

\section{J. C. Knox}

Marshall Space Flight Center

National Aeronautics and Space Administration

Huntsville, AL

James. E. Smith, Ph.D

Department of Chemical Engineering

University of Alabama in Huntsville

Huntsville, AL

ABSTRACT

The importance of the wall effect on packed beds in the adsorption and desorption of carbon dioxide, nitrogen, and water on molecular sieve $5 \mathrm{~A}$ of $0.127 \mathrm{~cm}$ in radius is examined experimentally and with onedimensional computer simulations. Experimental results are presented for a $22.5-\mathrm{cm}$ long by $4.5-\mathrm{cm}$ diameter cylindrical column with concentration measurements taken at various radial locations. The set of partial differential equations are solved using finite differences and Newmans's method. Comparison of test data with the axial-dispersed, non-isothermal, linear driving force model suggests that a two-dimensional model (submitted to Separatuin Science and Tchnology) is required for accurate simulation of the average column breakthrough concentration. Additional comparisons of test data with the model provided information on the interactive effects of carrier gas coadsorption with $\mathrm{CO}_{2}$, as well as $\mathrm{CO}_{2}-\mathrm{H}_{2} \mathrm{O}$ interactions. 


\section{Introduction}

In a packed bed, the presence of the confining walls can have a significant influence on the axial flow and therefore heat and mass transfer in the packed bed. The viscous shear force along the wall and the increase in porosity near the wall can have opposing effects on overall permeability. For values of tube to particle diameter ratio, $R$, less than about 7 , the permeability has been shown to increase above that of an infinite porous medium $(1,2,3)$. Between $R$ values of 7 and 30 , variations in bed packing may determine the governing influence. For $R$ values above 30, the influence is generally considered insignificant (3), although it was found to be important for an $R$ value greater than 100 in an adsorption study by Tobis and Vortmeyer (4).

Wall effects on packed bed processes can be significant in heat and mass transfer driven processes, since the value of $R$ is frequently within this sensitivity range. Examples are thermal swing adsorption beds where a heater matrix results in small rectangular columns (CDRA refs), wall-cooled catalytic reactors (5) and packed bed energy storage units (6).

In this work, we examine the influence of wall effects on mass and heat transfer during adsorption and desorption in a packed column. The experimental results for carbon dioxide and water adsorption in a nitrogen carrier gas provides information on the sensitivity of the adsorption to wall effects in a column with an intermediate tube to particle diameter ratio, $R$, of 15 . Adsorption breakthrough data is presented for various radial locations at the bed exit, which can be used as a measure of permeability or channeling along the column wall.

A computer model was developed based on the finite-differencing numerical technique. The model simulates gas adsorption and desorption in a flow-through bed. Single and multicomponent adsorption; thermal balances for the pellet, gas and canister, and the momentum equation are included. A twodimensional (radial and axial) model was also developed to predict the effect of flow channeling on adsorption and desorption and is described in a later paper (7).

\section{Experimental Apparatus and Results Adsorption Test System}

The test flow rate was scaled to give gas velocities similar to that in the proposed flight beds for the International Space Station Carbon Dioxide Removal Assembly. Instrumentation of the packed column 
includes temperature probes and sampling tubes for measurements at sorbent material endpoints and one intermediate point. To attain approximately adiabatic bed conditions, the column was first covered with Mansfield Q-fiber felt insulation, then wrapped with a thermal blanket of Mansfield Min-K material. For adsorption runs, an additional jacket fabricated of STS External Tank insulating foam was attached. The insulation, approximately 3 inches thick in all, was used with satisfactory results.

Instrumentation was provided for continuous measurement of packed column outlet $\mathrm{CO}_{2}$ and $\mathrm{H}_{2} \mathrm{O}$ concentration. The location of sensors and other equipment comprising the adsorbing apparatus are shown in Figure 1. The column bypass is used prior to the test start to ensure stable column inlet conditions.

The gas chromatograph, a Shimadzu GC-14A with CR601 integrator, was used to sample at three sample port locations to determine gas constituent volumetric fractions during the adsorption runs. The probe depth of the sampling tube at the column exit was adjusted to obtain a radial profile of the exit concentration during a series of identical $\mathrm{CO} 2$ adsorption tests.

\section{Column Dynamics Test Bed}

A small packed column with approximate dimensions of 2 inches in diameter and 20 inches long (Figure 2) located at Marshall Space Flight Center was used. The column may be packed with up to 20 inches of sorbent. A 10-inch packing was used in this study for quicker results and reduced thermal end effects. Placing 4.75 inches of glass beads at the two ends of the column eliminated the end effects.

\section{Procedure}

Experiments were performed on the insulated fixed-bed rig at MSFC. The sorbent is a 5A zeolite. Nitrogen is the carrier gas. Experiments begin with the column at ambient room temperature. The column bypass shown in Figure 1 was used to obtain intended inlet conditions before exposure of the column to the inlet gas. The GC sampling location was switched during the test to follow the sorbate mass transfer wave as it proceeded down the bed.

\section{Results and Discussion}

Figure 3 shows the water breakthrough at the column midpoint and outlet. Also shown is the $\mathrm{H}_{2} \mathrm{O}$ partial pressure of gas mixed by passing through glass beads downstream of the sorbent material. Note the mixed gas breaks through before the gas at the centerline, indicating that channeling has a significant effect on the process efficiency for the two-inch diameter column. 
To provide a measure of the radial variation in axial flow, adsorption tests of $\mathrm{CO}_{2}$ and $\mathrm{N}_{2}$ were conducted repeatedly with the exit sampling tube in different radial positions. The test results, shown in Figure 4, show a clear relationship between concentration and radial position. As observed for $\mathrm{H}_{2} \mathrm{O}$ breakthrough results, these results indicate greater permeability near the column wall. Since the heater core of the 4BMS (Four Bed Molecular Sievs) sorbent bed consists of channels roughly one-half inch in diameter, the channeling effect on $\mathrm{CO}_{2}$ removal will likely be significant. The results of the twodimensional model presented in part II also confirm that channeling has a significant effect on this adsorption process.

\section{Mathematical Model}

\section{Gas/Solid Equilibrium}

The model discussed here was developed using equilibrium data provided by the W.R Grace \& Company (8). Nitrogen adsorption was represented with the Langmuir expression:

$$
q_{i}^{*}=\frac{q_{m i} B_{i} P_{i}}{1+B_{i} P_{i}}
$$

Carbon dioxide and water adsorptions were correlated by the Langmuir-Freundlich equation (9):

$$
q_{i}^{*}=\frac{q_{m i} B_{i} P_{i}^{n_{i}}}{1+B_{i} P_{i}^{n_{i}}}
$$

Two approaches were used to solve for the amounts of gases adsorbed in the solid phase in equilibrium with the gas phase concentrations for multiple components. For simulations with $\mathrm{N}_{2}$ and $\mathrm{CO}_{2}$, the solution was obtained by an iterative procedure with the ideal adsorption solution theory (IAST) of Myers and Prasusnitz, (10). For the case of the Langmuir-Freundlich single component isotherm, one gets:

$$
\sum_{i=1}^{i=n} \frac{P y_{i}}{\left(\frac{\exp \left(\frac{\pi A n_{i}}{R T q_{m i}}\right)-1}{B_{i}}\right)^{\frac{1}{n_{i}}}}-1=0
$$


Knowing the total pressure and the solid temperature, a value for the spreading pressure $\pi$ is estimated and solution will be obtained by iteration until Eq. 3 is satisfied. For the simulations with $\mathrm{N}_{2}$, $\mathrm{H}_{2} \mathrm{O}$, and $\mathrm{CO}_{2}$ the approach based on the Langmuir-Freundlich equation for multicomponent systems was found to give a more accurate results than IAST model based on the non-ideality of $\mathrm{CO}_{2} / \mathrm{h}_{2} \mathrm{O}$, a paper is in the process for submision to discuss in details the use of IAST and Langmuir-Freundlich on the adsorption of $\mathrm{CO}_{2} / \mathrm{N}_{2}$ and $\mathrm{H}_{2} \mathrm{O} / \mathrm{CO}_{2} / \mathrm{N}_{2}$ on the $5 \mathrm{a}$ :

$$
q_{i}^{*}=\frac{q_{m i} B_{i} P_{i}^{n_{i}}}{1+\sum_{j} B_{j} P_{j}^{n_{j}}}
$$

The favorable agreement of simulation and test results using these correlations indicates low sensitivity to limitations of these correlations for components with differing adsorptivities. However, work continues towards a comprehensive gas/solid equilibrium model. For example, at low humidity levels, IAST accurately predicts multicomponent adsorption equilibria for $\mathrm{CO}_{2}$ and $\mathrm{H}_{2} \mathrm{O}$. At higher humidity levels, $\mathrm{CO}_{2}$ adsorption is under predicted, as discussed by Finn (11).

\section{Mass Balance Equation}

In the bulk stream of the gas within the bed, the material balance for the adsorbate concentration is

$$
\frac{\partial C_{i}}{\partial t}=D_{l} \frac{\partial^{2} C_{i}}{\partial x^{2}}-\frac{\partial u C_{i}}{\partial x}-\frac{1-\varepsilon}{\varepsilon} \frac{\partial \overline{q_{i}}}{\partial t}
$$

Boundary and initial conditions:

$$
\begin{aligned}
& \text { at } t<0, C_{i}=C_{i, 0} \text { for } 0 \leq x \leq L \\
& \text { at } t<0, q_{i}=q_{i, 0} \text { for } 0 \leq x \leq L \\
& \text { at } t \geq 0, C_{i}=C_{i, i} \text { for } x=0 \\
& \text { at } t \geq 0, \frac{\partial C_{i}}{\partial x}=0 \text { for } x=L
\end{aligned}
$$

The axial diffusion, $D_{l}$, was calculated using an equation from Edward and Richardson equation (12).

Assuming the ideal gas law $C_{i}=P / R T$ and knowing $\sum y_{i}=1$, the above equation can be recast into an overall mass balance equation, 


$$
\begin{aligned}
& \frac{\partial P}{\partial t}=D_{l} \frac{\partial^{2} P}{\partial x^{2}}-u \frac{\partial P}{\partial x}-P \frac{\partial u}{\partial x}+\frac{P}{T_{g}}\left(\frac{\partial T}{\partial t}-\right. \\
& \left.D_{l} \frac{\partial^{2} T}{\partial x^{2}}+u \frac{\partial T}{\partial x}\right)-R T \frac{1-\varepsilon}{\varepsilon} \sum_{i=1}^{n} \frac{\partial \overline{q_{i}}}{\partial t}
\end{aligned}
$$

This equation was used to compute axial velocity in the bed.

\section{Gas Phase Energy Equation}

The change of gas temperature with respect to time is due to heat flux from the solid to the gas plus convection of heat due to the fluid flow, as shown by the following equation:

$$
\begin{aligned}
& \rho_{g} c_{p g} \frac{\partial T_{g}}{\partial t}=k_{f} \frac{\partial^{2} T_{g}}{\partial x^{2}}-u \rho_{g} c_{p g} \frac{\partial T_{g}}{\partial x}+ \\
& \frac{1-\varepsilon}{\varepsilon} h_{s} a_{s}\left(T_{s}-T_{g}\right)-\frac{4 h_{w}}{\varepsilon d}\left(T_{g}-T_{w}\right)
\end{aligned}
$$

Boundary and initial conditions:

$$
\begin{aligned}
& \text { at } t<0, T_{g}=T_{g, 0} \text { for } 0 \leq x \leq L \\
& \text { at } t \geq 0, T_{g}=T_{i} \quad \text { for } x=0 \\
& \text { at } t \geq 0, \frac{\partial T_{g}}{\partial x}=0 \text { for } x=L
\end{aligned}
$$

Note that $T_{w}$ is calculated in Eq 12 .

\section{Solid Phase Energy Equation}

The energy equation for the solid phase includes the term for heat flux from the solid phase to the gas phase plus heat generation due to adsorption.

$$
\rho_{s} c_{p s} \frac{\partial T_{s}}{\partial t}=k_{s} \frac{\partial^{2} T_{s}}{\partial x^{2}}+h_{s} a_{s}\left(T_{g}-T_{s}\right)-\sum_{i=1}^{n} \Delta H_{i} \frac{\partial \overline{q_{i}}}{\partial t}
$$

Boundary and initial conditions:

$$
\begin{aligned}
& \text { at } t<0, T_{s}=T_{s, 0} \text { for } 0 \leq x \leq L \\
& \text { at } t \geq 0, T_{s}=T_{i} \quad \text { for } x=0 \\
& \text { at } t \geq 0, \frac{\partial T_{s}}{\partial x}=0 \text { for } x=L
\end{aligned}
$$




\section{Column Wall Energy Equation}

The wall temperature $T_{w}$ is given by:

$$
\rho_{w} C_{p w} \frac{\partial T_{w}}{\partial t}=2 \pi R_{i} h_{w}\left(T_{g}-T_{w^{\prime}}\right)-2 \pi R_{o} h_{o}\left(T_{w}-T_{o}\right)
$$

Initial condition:

$$
\text { at } t<0, T_{w}=T_{w, 0}
$$

Axial conduction is neglected since the area of heat transfer from the fluid to the wall is an order of magnitude larger than the area in the axial direction. This is analogous to heat conduction in a slab.

\section{Momentum Equation}

The Ergun equation $(13,14)$ is used to estimate the pressure drop,

$$
\frac{d P}{d x}=-\frac{\mu}{K} u-\rho C u^{2}
$$

where $C$ is the inertial coefficient. The empirical coefficients $K$ and $C$ are given by relations developed by Ergun for flow in a packed bed of spherical particle;

$$
\begin{aligned}
& K=\frac{d^{2} \varepsilon^{3}}{150(1-\varepsilon)^{2}} \\
& C=\frac{1.75(1-\varepsilon)}{d \varepsilon^{3}}
\end{aligned}
$$

Using gas velocity as calculated in Eq. 7, the total pressure was found with Eq. 14.

\section{Solid Phase Transport Equation}

Mass transfer of solute from the bulk gas to sorbed state is driven by the difference in the actual adsorbed quantity versus the quantity that would be adsorbed at equilibrium conditions. In general, the mass transfer mechanism of an adsorption process includes four steps: fluid-film diffusion, pore diffusion, adsorption rate, and surface diffusion. Adsorption rate can be neglected since it is much greater than the diffusion rates as discussed by Yang, (15).

Zeolite sorbents consist of crystals, in the size range of $1-9 \mu \mathrm{m}$, which are pelletized with a small amount of binder. Macropore (spaces between the crystals) and micropore (intracrystalline) diffusion must 
in general be considered. However, for molecules in the size range of $\mathrm{CO}_{2}$ adsorbing onto $5 \mathrm{~A}$ the diffusion rate inside the pellet has been shown to be controlled by intracrystalline diffusion (16).

Assuming the intracrystalline diffusion governs the overall mass transfer, the linear driving force (LDF) model based on Glueckauf, (17) may be used:

$$
\frac{\partial \bar{q}_{i}}{\partial t}=k_{e f} a_{s}\left(\dot{q}_{i}-\bar{q}_{i}\right)
$$

where $k_{e f}$ is obtained by experimental procedure and $a_{s}$ is the interfacial surface area. The justification of assuming a linear diving force to model the adsorbed concentration in the solid phase has been well established by other researchers such as, $(16,21,22,23)$ to name a few.

Gas to pellet heat transfer coefficients obtained from the Petrovic and Thodos (18), for $\mathrm{CO}_{2}, \mathrm{H}_{2} \mathrm{O}$, and $\mathrm{N}_{2} \times$ were $.0875, .1002$, and $.0844 \mathrm{~cm} / \mathrm{sec}$, respectively. The empirically obtained mass transfer coefficients using the LDF model for $\mathrm{CO}_{2}, \mathrm{H}_{2} \mathrm{O}$, and $\mathrm{N}_{2}$ were $1.27 \times 10^{-4}, 2.625 \times 10^{-5}$, and $3.75 \times 10^{-4} \mathrm{~cm} / \mathrm{sec}$, respectively. Since the overall mass transfer rate is three orders of magnitudes smaller than the calculated mass transfer rate from the gas phase to the pellet surface, the latter was neglected.

\section{Numerical Solution}

The solution of this system must be obtained numerically. For an $n$ component mixture, the numerical model will require the solution of several coupled differential equations: $n-1$ mass balance equations, $n$ rate equations and equilibrium isotherms, the overall mass balance equation, the momentum equation, and the heat balance equation each for the fluid phase, gas phase, and column wall.

In this work, the PDE's were discretized using the finite difference method. The first order approximation was used for the time dimension. First order boundary nodes and second order internal nodes were used for spacial coordinates. The set of discretized finite difference equations was solved simultaneously by an implicit method. The method of Newman $(19,20)$ was found to be effective for the steep gradient of mass concentration along the bed length, Newman, 1967and 1968.

50 nodes represented the column length. The time step was increased from 3.6 to 60 seconds as the

solution progressed. Convergence was assumed when $\left(C^{n+1}+C^{n}\right) / C^{n+1}$ was less than $1.0 \times 10^{-4}$ for each grid point. Here, $C$ is the gas phase concentration, $n$ indicates the previous time step, and $n+1$ the current time step. 


\section{Results}

In this section we present modeling results which illustrate the importance of accurately simulating critical adsorption processes, and comparisons of model results with test data. Simulations were performed on an ALPHA VAX computer. Experiments were performed on the insulated fixed-bed rig at MSFC. The sorbent is a $5 \mathrm{~A}$ zeolite. Nitrogen is the carrier gas. Experiments begin with the column at ambient room temperature.

\section{Thermal Effects Modeling}

Heat transfer coefficients are found by comparison of the thermal model with heating of the sub-scale column with an inert gas, shown in Figure 5.

Nitrogen was heated to a temperature of $350^{\circ} \mathrm{F}$ and passed through an initially cold column. The markers are the measured temperatures at the inlet, midpoint, and exit of the column. The lines are the results from simulation. Resultant heat transfer coefficients are $2.5 \mathrm{BTU} / \mathrm{hr}-\mathrm{ft}^{2}$ from the fluid stream to the canister wall, and $0.25 \mathrm{BTU} / \mathrm{hr}-\mathrm{ft}^{2}$ from the canister wall to the atmosphere. These values are used in the simulations described below.

\section{Nitrogen Coadsorption Effects Modeling}

The importance of not neglecting the nitrogen co-adsorption with $\mathrm{CO}_{2}$ is shown in Figure 6. $\mathrm{CO}_{2}$ in nitrogen at $6.2 \mathrm{mmHg}$ was passed through an initially clean zeolite column. The gas at the column centerline was analyzed periodically at the column inlet, midpoint, and outlet. These results are compared with simulations that either included (solid lines) or neglected (dashed lines) the effect of nitrogen. Nitrogen clearly has a noticeable effect; however the simulations that included $\mathrm{N}_{2}$ adsorption over-predicted the effect slightly.

The thermal sensitivity to $\mathrm{N}_{2}$ co-adsorption is shown in Figure 7 . The agreement is much better when the heat of adsorption of nitrogen is included. A decrease in temperature occurs at 0.15 hours in both the test data and the simulation, due to $\mathrm{N}_{2}$ displacement by $\mathrm{CO}_{2}$ and $\mathrm{N}_{2}$ reduces the bed capacity and lower overall bed temperatures through desorption. 


\section{Water Coadsorption Effects Modeling}

Verification of the model for $\mathrm{CO}_{2} / \mathrm{H}_{2} \mathrm{O} / \mathrm{N}_{2}$ co-adsorption is shown in figures 8 to 10 . These three figures illustrate testing and simulation runs for adsorption of water at $6.3 \mathrm{mmHg}$ and $\mathrm{CO}_{2}$ at $2.89 \mathrm{mmHg}$ in a carrier gas of nitrogen. All figures show test data as markers and simulation data as lines.

Figure 8 illustrates the roll-up phenomenon as adsorbed $\mathrm{CO}_{2}$ is driven off by water, and the $\mathrm{CO}_{2}$ partial pressure rises above the inlet level temporarily. The effect should be larger at the column outlet than midpoint as shown by test data.

Figure 9 shows the water breakthrough at the column midpoint and outlet. Also shown is the $\mathrm{H}_{2} \mathrm{O}$ partial pressure of gas mixed by passing through glass beads downstream of the sorbent material. Note the mixed gas breaks through before the gas at the centerline, indicating that channeling is significant along the walls of the two-inch diameter column. Since the heater core of the 4BMS sorbent bed consists of channels roughly one-half inch in diameter, the channeling effect on $\mathrm{CO}_{2}$ removal will be significant. The results of the two-dimensional model (not shown here) confirm that channeling has a significant effect on this adsorption process. Finally, Figure 10 shows the temperatures of the bed at midpoint and outlet.

\section{Bed Regeneration}

Desorption of $\mathrm{CO}_{2}$ test results in comparison with model are shown by the solid lines in Figures 11 and 12. After the bed was saturated with $\mathrm{CO}_{2}$, the regeneration process was started by using $\mathrm{N}_{2}$ as the purge gas. As it shown the effluent concentration of $\mathrm{CO}_{2}$ has sharp drop at first few minutes and the slope of the breakthrough flats out as time goes by. The initial drop in temperature is due to heat of desorption and finally reaches the inlet condition when there is no depletion of $\mathrm{CO}_{2}$ from the bed. The same mass transfer coefficient of .017 was used. The model predicts both temperature and breakthrough fairly well. The IAST was used to predict the mixtureisotherm of $\mathrm{CO}_{2} / \mathrm{N}_{2}$

Desorption of $\mathrm{H}_{2} \mathrm{O}$ test results in comparison with the model are shown by the solid lines in Figures 13 and 14. The results of the partial pressure of $\mathrm{H}_{2} \mathrm{O}$ and temperature profile of this 1-D desorption model are not in good agreement with the test data. The model shows a fast reduction of $\mathrm{H}_{2} \mathrm{O}$ partial pressure in gas phase. A mass transfer coefficient as large as $.04 \mathrm{ft} / \mathrm{hr}$, in contrast with $.0035 \mathrm{ft} / \mathrm{hr}$ in the case of $\mathrm{H}_{2} \mathrm{O}$ adsorption, was used. Generally, there shouldn't be such a large difference between the two coefficients. Even with this large mass transfer coefficient the desorption of $\mathrm{H}_{2} \mathrm{O}$ from the bed was insufficient to 
increase the $\mathrm{H}_{2} \mathrm{O}$ partial pressure in the gas phase. In contrast with adsorption process, any small discrepancy of $\mathrm{H}_{2} \mathrm{O}$ partial pressure with test data will remain as a error throughout the completion of the test. In adsorption any small error at any point in the bed, if it is caused by the isotherm at some partial pressure of the feed will be eliminated at a later time because of the correct value of isotherm at a larger partial pressure of the feed. This can be seen from the early breakthrough observed by other researcher. The obvious reason is that the equilibrium isotherm at low partial pressures are being underestimated. It is also possible that the equilibrium isotherm of $\mathrm{H}_{2} \mathrm{O}$ on $5 \mathrm{~A}$ material shows hysteresis so that the apparent equilibrium pressure observed in adsorption and desorption experiment are different. The concentration of a key component, $\mathrm{CO}_{2}$, is affected by the presence of the non-key component, $\mathrm{N}_{2}$, in $\mathrm{CO}_{2} / \mathrm{N}_{2}$ adsorption. $\mathrm{CO}_{2}$ effluent concentration overshoots its inlet concentration because of $\mathrm{H}_{2} \mathrm{O}$ displacement (more easily adsorbed) component. The height of this roll-up is increased with the inlet concentration of $\mathrm{H}_{2} \mathrm{O}$ component. The most significant contribution to the difference in model and experimental results of $\mathrm{H}_{2} \mathrm{O}$ desorption pretend to that fact that the duration of an $\mathrm{H}_{2} \mathrm{O}$ adsorption run takes about fifteen hours for completion of a test. Also, the desorption run duration takes ten to twelve hours. During this long duration the temperature of location where the test took place varied about $10-15$ degree ${ }^{\circ} \mathrm{F}$, during the night. This in turn affects the saturated air that was used to saturate the column. Therefore it is accurate to conclude the amount of $\mathrm{H}_{2} \mathrm{O}$ adsorbed on the bed is less than what is assumed in model.

On the basis of the data presented here, and other comparisons between desorption test data and simulation results not yet published, this computer model meets its primary objective - achieving predictive capability. Enhancements to the model as discussed should increase its accuracy. Efforts are continuing to develop on the integrated 4BMS simulation, equilibrium isotherms, heat and mass transfer coefficients, and verification data.

\section{Conclusions}

Based on analytical and experimental investigation of convective flows in porous media the following conclusions are drawn:

- The experimental results from the laboratory scale-fixed bed adsorber are quantitatively consistent with the one-dimensional model at the column center. The average concentration of cross sectional bed obtained by test result deviates from the column center concentration appreciably. This indicates the 
strong effects of porosity variation along the radial direction of column bed on the temperature, concentration, and velocity field. Results from the model were encouraging and contributed to the decision to model the dynamic behavior of the column in two-dimensions.

- A linear driving force mass transfer model provides a reasonable fit to experimental adsorption data.

- The concentration of a key component, $\mathrm{CO}_{2}$, is affected by the presence of the non-key component, $\mathrm{N}_{2}$, in $\mathrm{CO}_{2} / \mathrm{N}_{2}$ adsorption. $\mathrm{CO}_{2}$ effluent concentration overshoots its inlet concentration because of $\mathrm{H}_{2} \mathrm{O}$ displacement (more easily adsorbed) component. The height of this roll-up is increased with the inlet concentration of $\mathrm{H}_{2} \mathrm{O}$ component.

\section{NOMENCLATURE}

A Surface area of pellets per unit volume of pellet $\mathrm{ft}^{2} / \mathrm{ft}^{3}$

A Surface area $\mathrm{ft}^{2}$

$B \quad$ Langmuir constant

C Constant in Darcy equation

C Gas stream concentration, $\mathrm{lb}$ mole/ $/ \mathrm{ft}^{3}$

$c_{i p} \quad$ Gas phase concentration of $\mathrm{i}^{\text {th }}$ component in the pores of particles, $\mathrm{lb}$ mole $/ \mathrm{ft}^{3}$

$\bar{C}_{i p} \quad$ Volume average pore Gas phase concentration of $\mathrm{i}^{\text {th }}$ component $\mathrm{i}$, lb mole/ft $\mathrm{ft}^{3}$

$C_{i}^{s} \quad$ Gas phase concentration of $\mathrm{i}^{\text {th }}$ component at the surface of the solid phase $\mathrm{lb}$ mole/ $/ \mathrm{ft}^{3}$

$C_{i, 0} \quad$ Gas phase concentration of $\mathrm{i}^{\text {th }}$ component at boundary or initial $\mathrm{lb}$ mole/ $/ \mathrm{ft}^{3}$

$C_{p g} \quad$ Heat capacity of gas phase, Btu/lbm-R

$C_{p s} \quad$ Heat capacity of solid particle, Btu/lbm-R

$C_{p w} \quad$ Heat capacity of column wall, Btu/lbm-R

$D \quad$ diffusivity, $\mathrm{ft}^{2} / \mathrm{hr}$

$D_{l} \quad$ Axial diffusion, $\mathrm{ft}^{2} / \mathrm{hr}$

$H_{o} \quad$ Effective Heat transfer coefficient for column insulation, Btu/ft $\mathrm{t}^{2}-\mathrm{hr}$

$H_{w} \quad$ Heat transfer coefficient between the gas stream and the column wall, Btu/ft $\mathrm{t}^{2} \mathrm{hr}$ 
$H_{s} \quad$ Heat transfer coefficient between the gas stream and the sorbent, $\mathrm{Btu} / \mathrm{ft}^{2}$-hr

$\Delta H \quad$ Heat of Adsorption, Btu/lb mole

$K \quad$ Constant in Darcy equation

$K_{f} \quad$ axial conductivity of fluid flow, Btw/ft-hr-R

$K_{s} \quad$ Solid thermal conductivity, Btu/ft-hr-R

$M_{i} \quad$ Molecular weight of adsorbate $\mathrm{i}, \mathrm{lb} / \mathrm{lb}$ mole

$N \quad$ Number of component

$P \quad$ Total pressure, $\mathrm{mmHg}$ or $\mathrm{lbf} / \mathrm{ft}^{2}$

$P_{i} \quad$ Partial pressure of component i, mmHg or $\mathrm{lbf} / \mathrm{ft}^{2}$

$Q \quad$ Amount adsorbed in the solid, $\mathrm{lb}$ moles $/ \mathrm{ft}^{3}$ of solid

$\ddot{q}_{i} \quad$ Solid phase concentration of $\mathrm{i}^{\text {th }}$ component in equilibrium with gas phase, lbs moles $/ \mathrm{ft}^{3}$ of solid

$q_{m i} \quad$ Langmuir constant

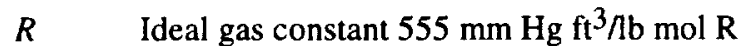

$R_{i} \quad$ Inside wall diameter of column, $\mathrm{ft}$

$R_{o} \quad$ Outside wall diameter of column, $\mathrm{ft}$

$R_{p} \quad$ Particle radius, $\mathrm{ft}$

$T \quad$ Time, $\mathrm{hr}$

T Temperature R

$T_{o} \quad$ Ambient temperature, $\mathrm{R}$

$T_{g} \quad$ gas temperature, $\mathrm{R}$

$T_{w} \quad$ Wall temperature, $\mathrm{R}$

$T_{s} \quad$ Solid temperature, $\mathrm{R}$

$U \quad$ Interstitial velocity, $\mathrm{ft} / \mathrm{hr}$

Greek Letters

$\varepsilon \quad$ External bed void volume

$\rho_{p g} \quad$ Density of gas phase, $\mathrm{lb}$ mole/ $/ \mathrm{ft}^{3}$ 


$$
\begin{array}{ll}
\rho_{s} & \text { Density of solid phase, } \mathrm{lbs} / \mathrm{ft}^{3} \\
\rho_{w} & \text { Density of column wall, } \mathrm{lb} \text { mole } / \mathrm{ft}^{3} \\
\pi & \text { Constant or spreading pressure } \\
\Delta H & \text { Heat of adsorption, BTU/lb of solid }
\end{array}
$$

\begin{tabular}{|c|c|}
\hline$i$ & $\mathrm{i}^{\text {th }}$ component \\
\hline$e$ & Effective \\
\hline$o$ & Outside, initia \\
\hline$p g$ & Gas phase \\
\hline$p s$ & Solid phase \\
\hline$s$ & Surface \\
\hline$t$ & total \\
\hline$w$ & Wall \\
\hline
\end{tabular}

\section{Subscripts}

Superscripts

\section{REFERENCES}

1- Nield, D. A., "Alternative Model for Wall Effect in Laminar Flow of Fluid through a Packed Column", AIChE J., 29, 688, 1983.

2- Cohen, Y., and Metzner, A. B. "Wall Effect in Laminar Flow of Fluids through Packed Beds," AIChe J., 27, 705, 1981.

3- Chu, C.F., and Ng, K.M., "Flow in Packed Tubes with a Small Tube to Particle Diameter Ratio", AIChE J., 35, 148-158, 1989. 
4- Tobis, J. and Vortmeyer, D., "Near Wall Channeling Effect on Isothermal Constant-Pattern Adsorption, Chem. Eng. Sci., 1363-1369, 1988.

5- Cheng, P. and Zhu, H., "Effects of Radial Thermal Dispersion on Fully-Developed Forced Convection in Cylindrical Packed Tubes," J. Heat Mass Transfer, 30, 2373-2383, 1987.

6- Beasley, D. E., and Clark, J. A., "Transient Response of a Packed Bed for Thermal Energy Storage," J. Heat Mass Transfer, 27, 1659-1669, 1984.

7- Mohamadinejad, H., Knox, J., “

8- "Davison Molecular Sieves Adsorption Equilibria", W. R. Grace \& Co., Davison Chemical Division, Baltimore Maryland.

9- Langmuir, I., " The Adsorption of Gases on Plane Surface of Glass, Mica, Platinum," J. Amer. Chem. Soc., 40, 1361 (1918).

10- Myers, A. L., and J. M., Prausnitz, "Thermodynamics of Mixed-Gas Adsorption," AICHE J., $11,121,1965$.

11- Finn, J.E.“4BMS Adsorption Characterization Project Status Report”, Ames Research Center, Moffet Field, California, 1996.

12- Edwards, M. F., and J. F. Richardson, "Gas Dispersion in Packed Beds," Chem. Eng. Sci., 23, 109, 1968.

13- Ergun, S., "Fluid Flow Through Packed Column," Chem. Eng. Prog., 48, 89-94, 1952.

14- Beavers, G.S. and Sparrow, E.M., "Non-Darcy Flow through Fibrous Porous Media," J. Applied Mech., 36, 711-714, 1969.

15- Yang, R. T., Gas Separation by Adsorption Process, Butterworths, Boston, 1987.

16- Ruthven, D. M., Principle of Adsorption and Adsorption Processes, John Wiley \& Sons, Inc., New York, 1984.

17 .

Glueckauf. E., "Theory of Chromatography-Part 10," Trans. Faraday. Soc., 51, 1540, 1955.

18- Petrovic, L. J., and G. Thodos, "Mass Transfer in the Flow of Gases through Packed Bed," Ind. Eng. Chem. Fundam., 7, 2, 274, 1968.

19- Newman, J., "Numerical Solution Of Coupled, Ordinary Differential Equations", UCRL-17739, Lawrence Radiation Laboratory, University of California, Berkeley, August, 1967. 
20- Newman, J., "Numerical Solution of Coupled, Ordinary Differential Equations," Ind and Eng. Chem." Fund, 7, 514-517, 1968.

21- DO, D.D., "Sorption of Bimodal Microporous Solids With an Irreversible Isotherm," Chemical Engineering Science", Vol. 44, No. 8, pp. 1707-1713, 1989.

22- Grag, D. R., and Ruthven, D.M., "The Effect of Concentration Dependence of Diffusivity on Zeolitic Sorption Curves," Chemical Engineering Science," Vol. 27, pp. 417-423, 1972.

23- Sargent, R. W. H. and Whitford, C. J., 1971, Diffusion of Carbon Dioxide in type 5A Molecular Sieve, in Molecular Sieve II, "Advances in Chemistry Series 102, American Chemistry Society, Washington, DC. 


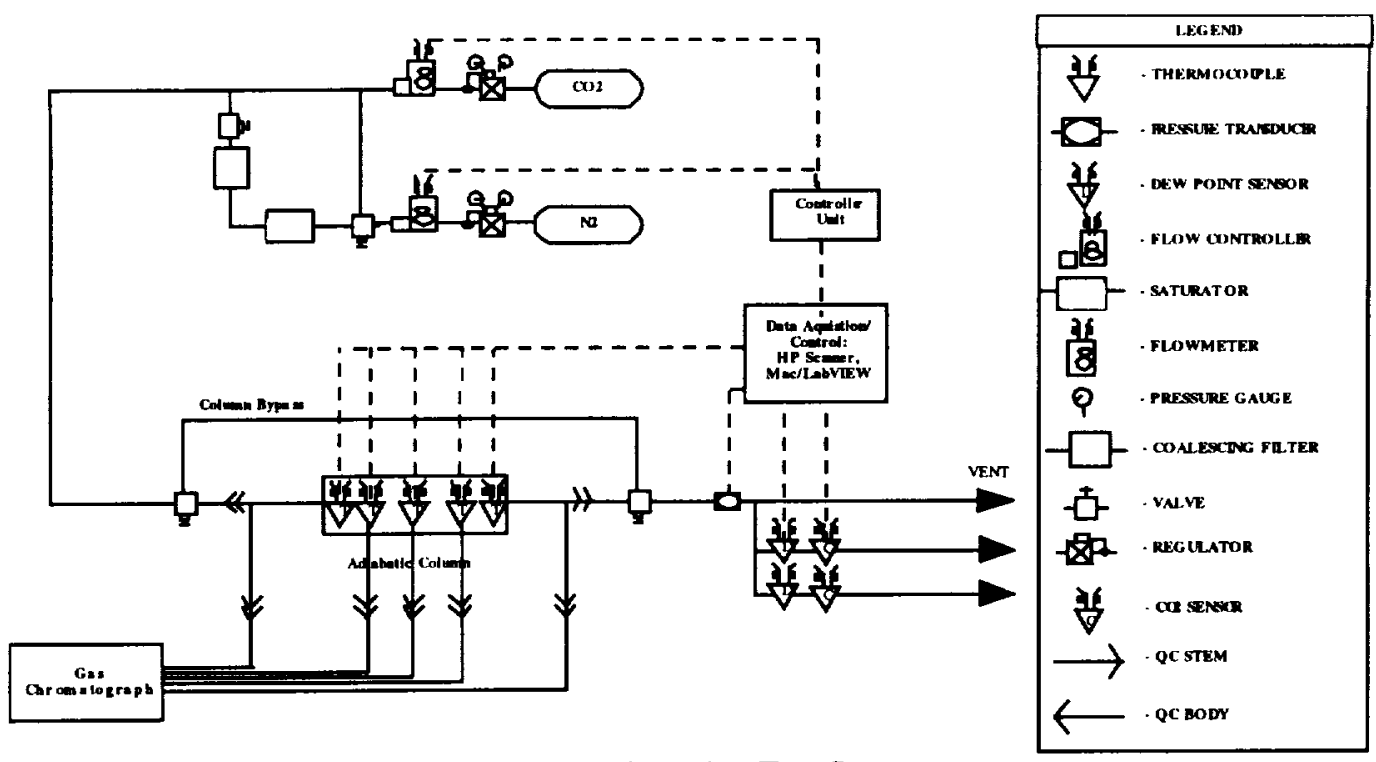

Figure 1: Adsorption Test System 

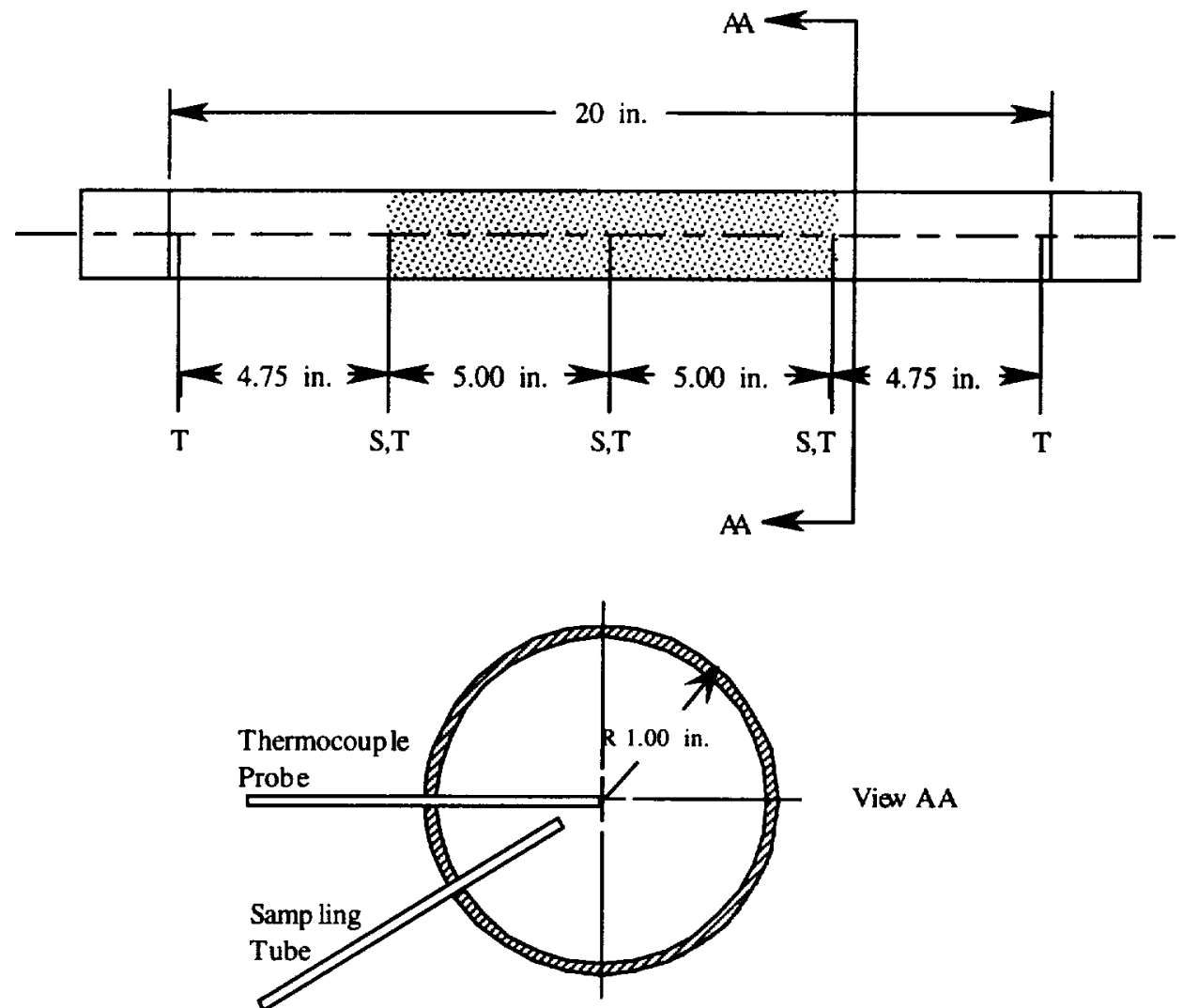

Figure 2: Column Sensor and Sampling Tube Location 


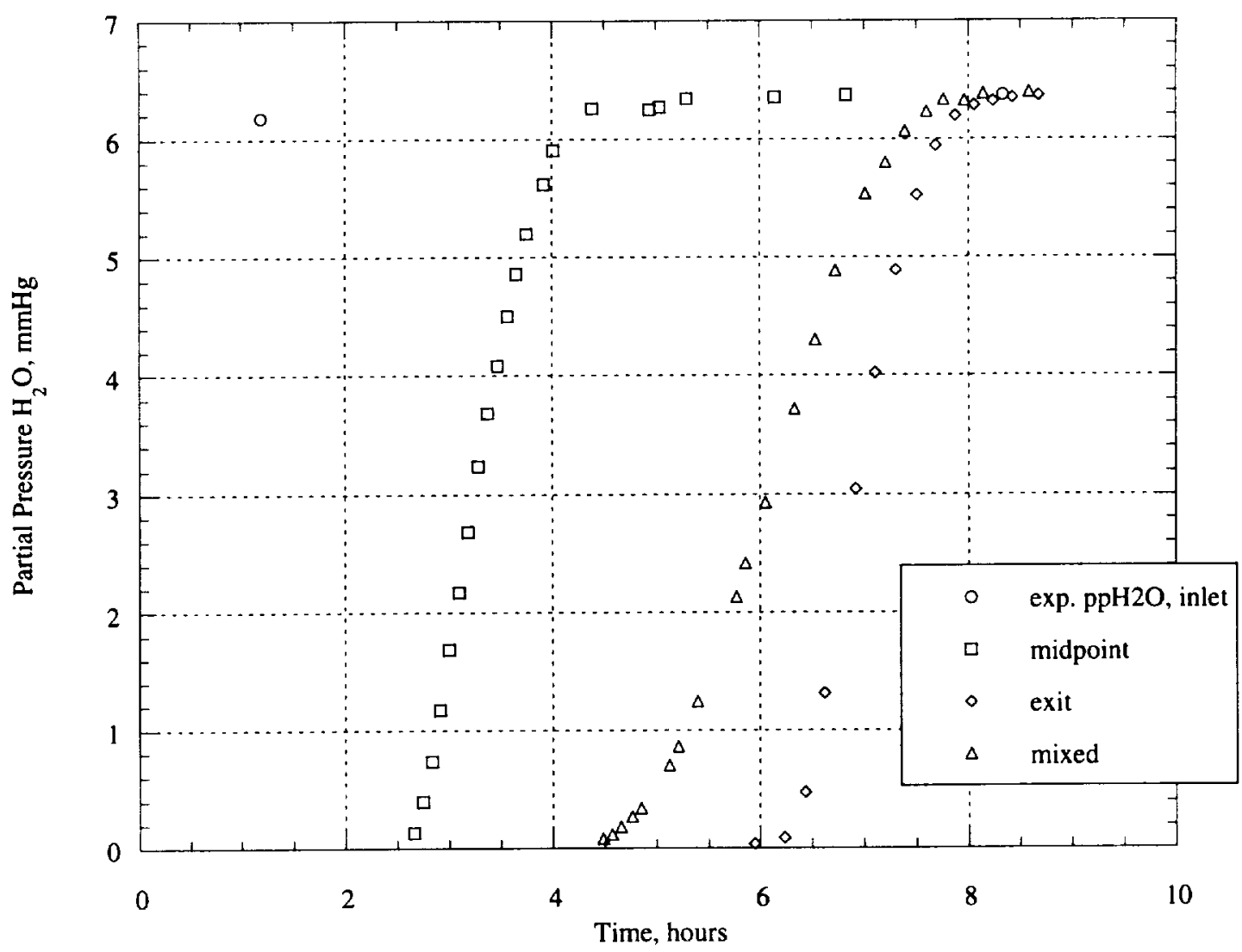

Figure 3: $\mathrm{H} 2 \mathrm{O}$ Breahthrough for $\mathrm{Co} 2 / \mathrm{H} 2 \mathrm{O} / \mathrm{N} 2$ Coadsorption 


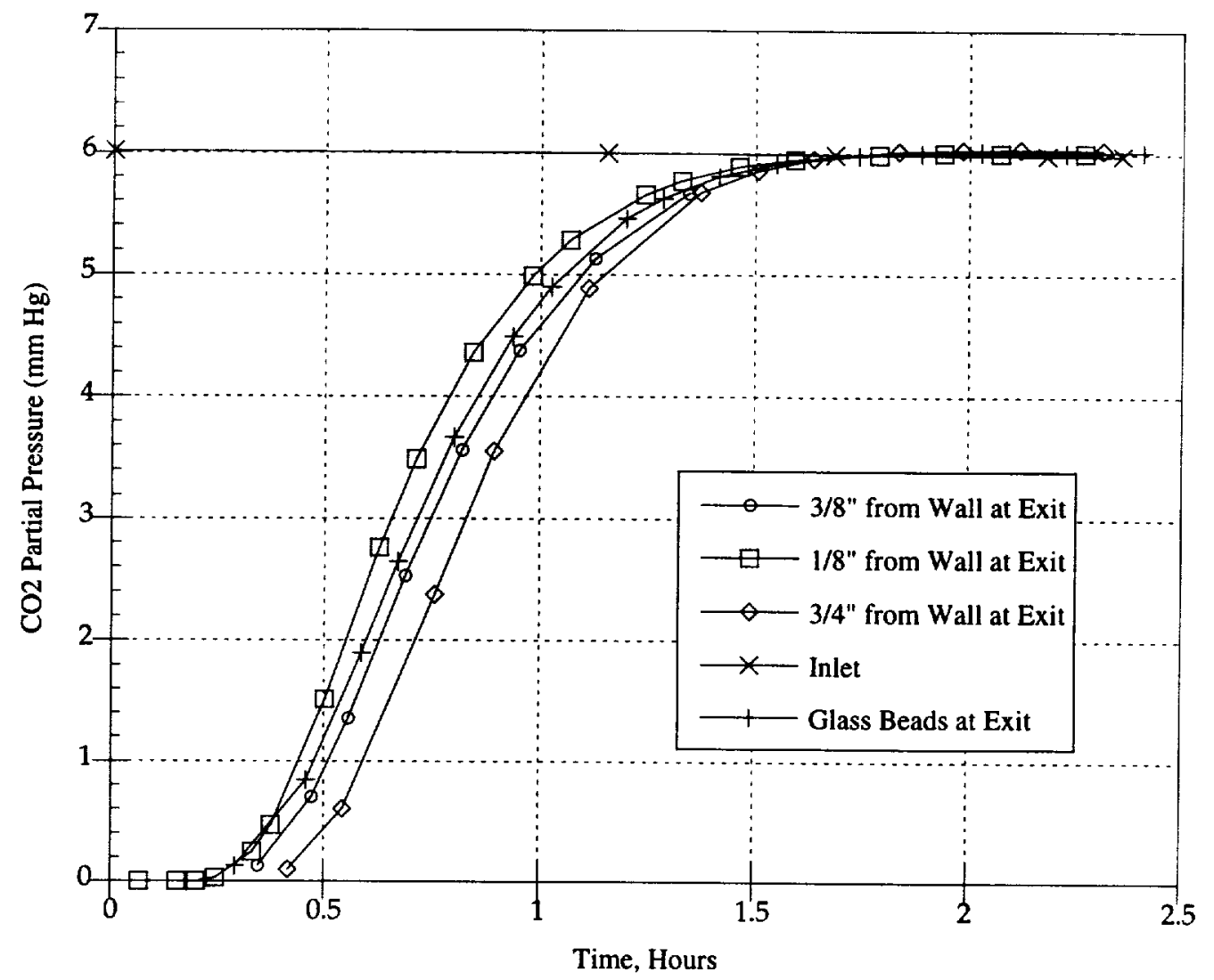

Figure 4: $\mathrm{CO} 2$ Breakthrough for Various Radial Positions 


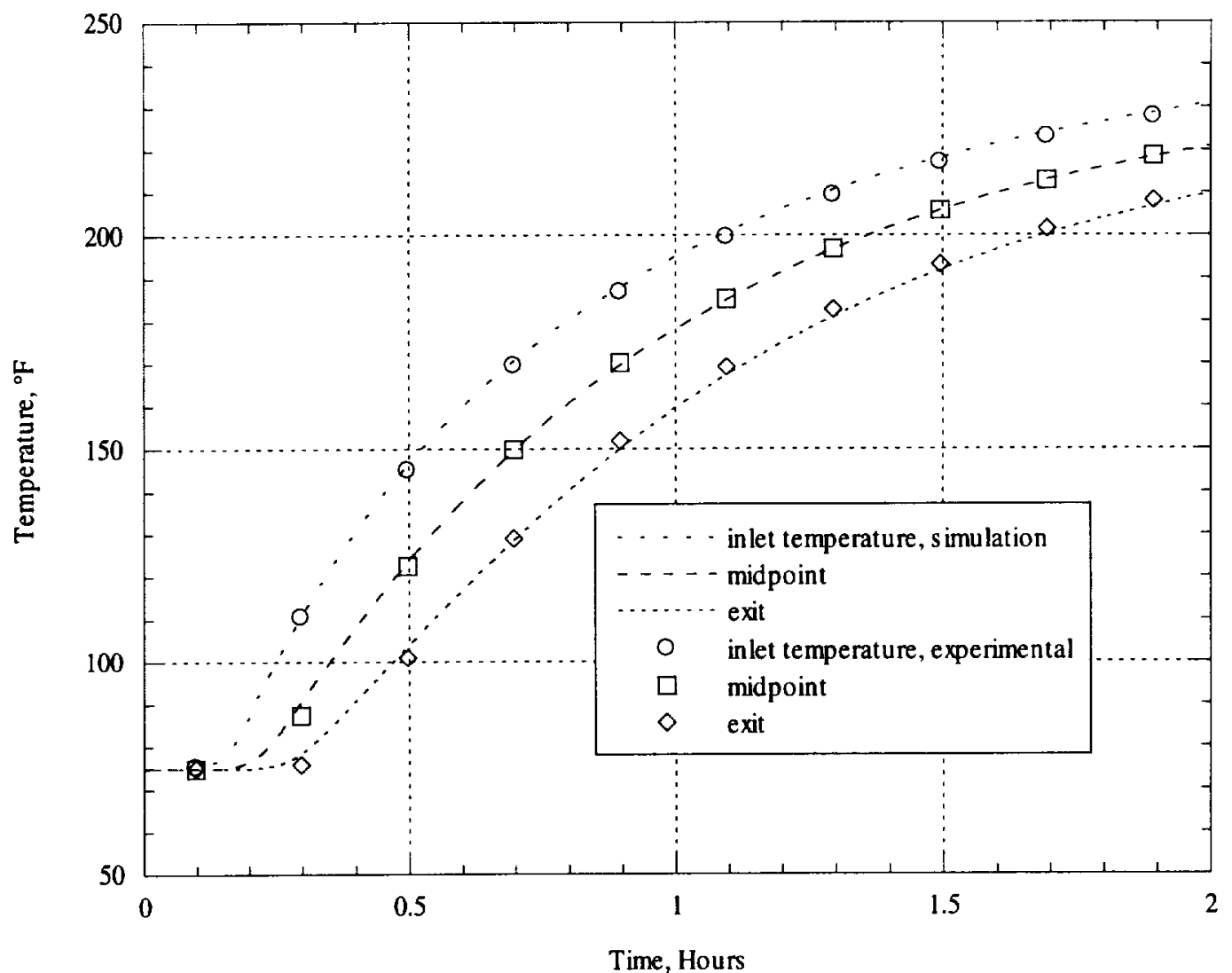

Figure 5: Thermal Model Validation 


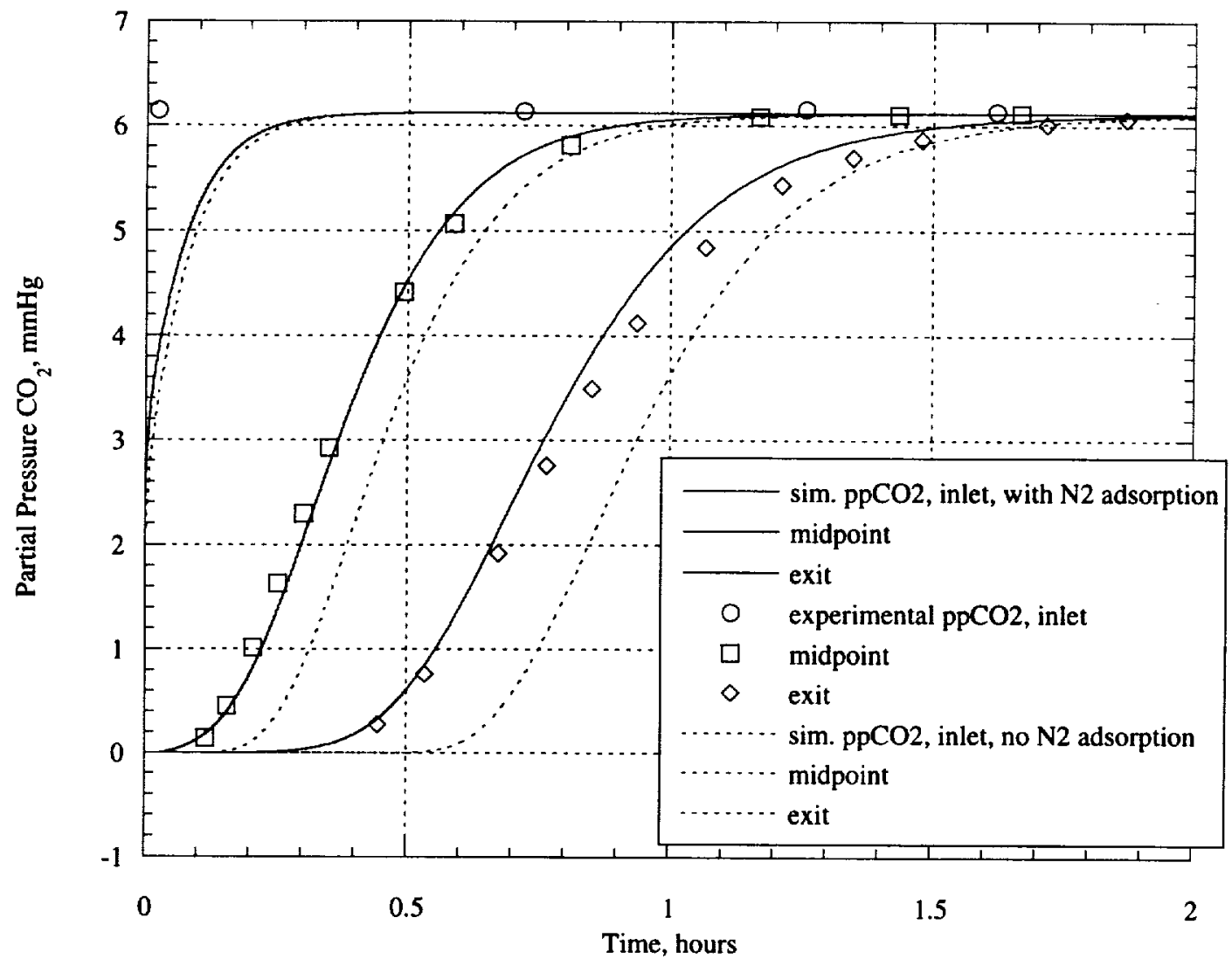

Figure 6: Effect of Nitrogren Coadsorption on $\mathrm{CO} 2$ breakthrough 


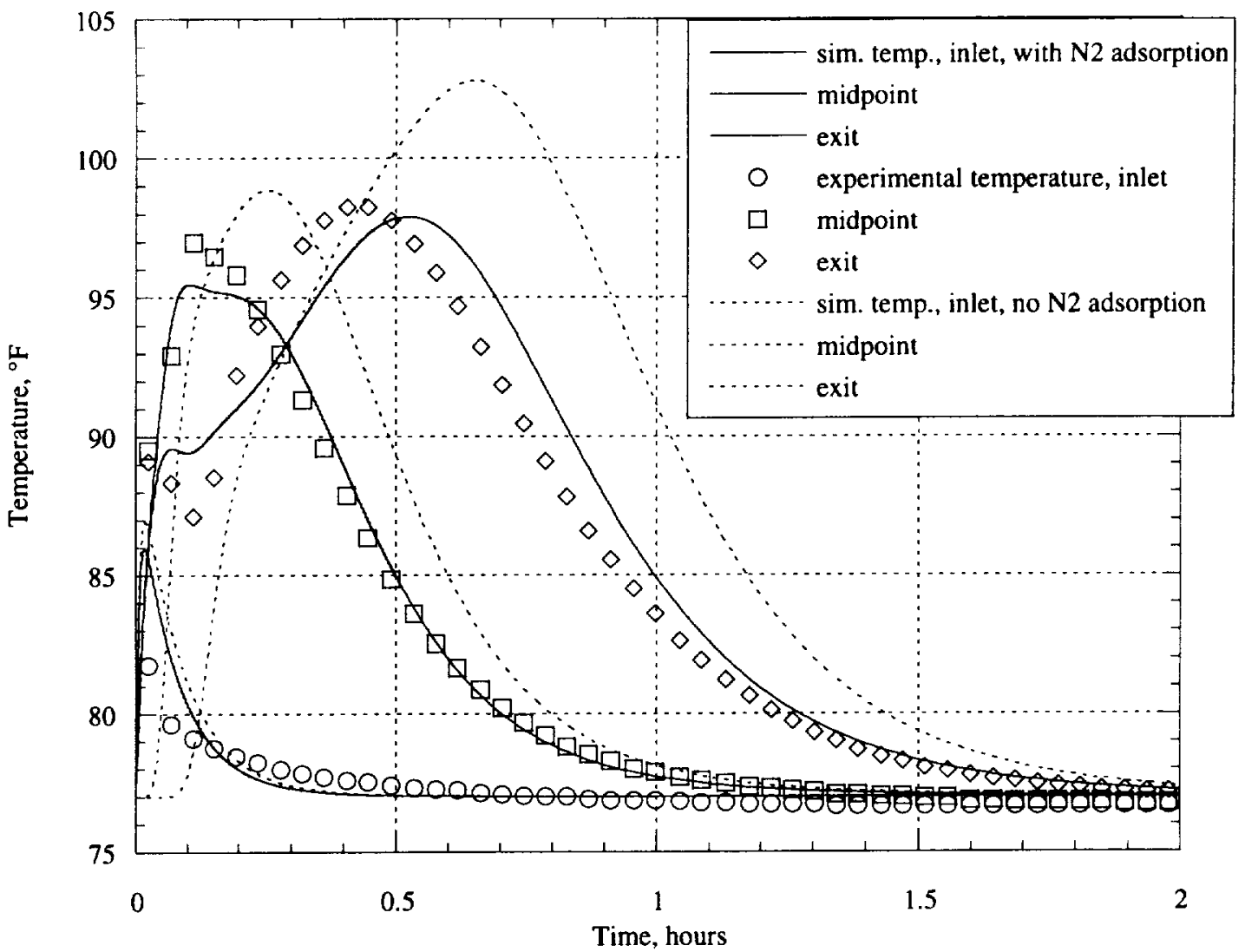

Figure 7: Heat Transfer Effect of Nitrogen Coadsorption 


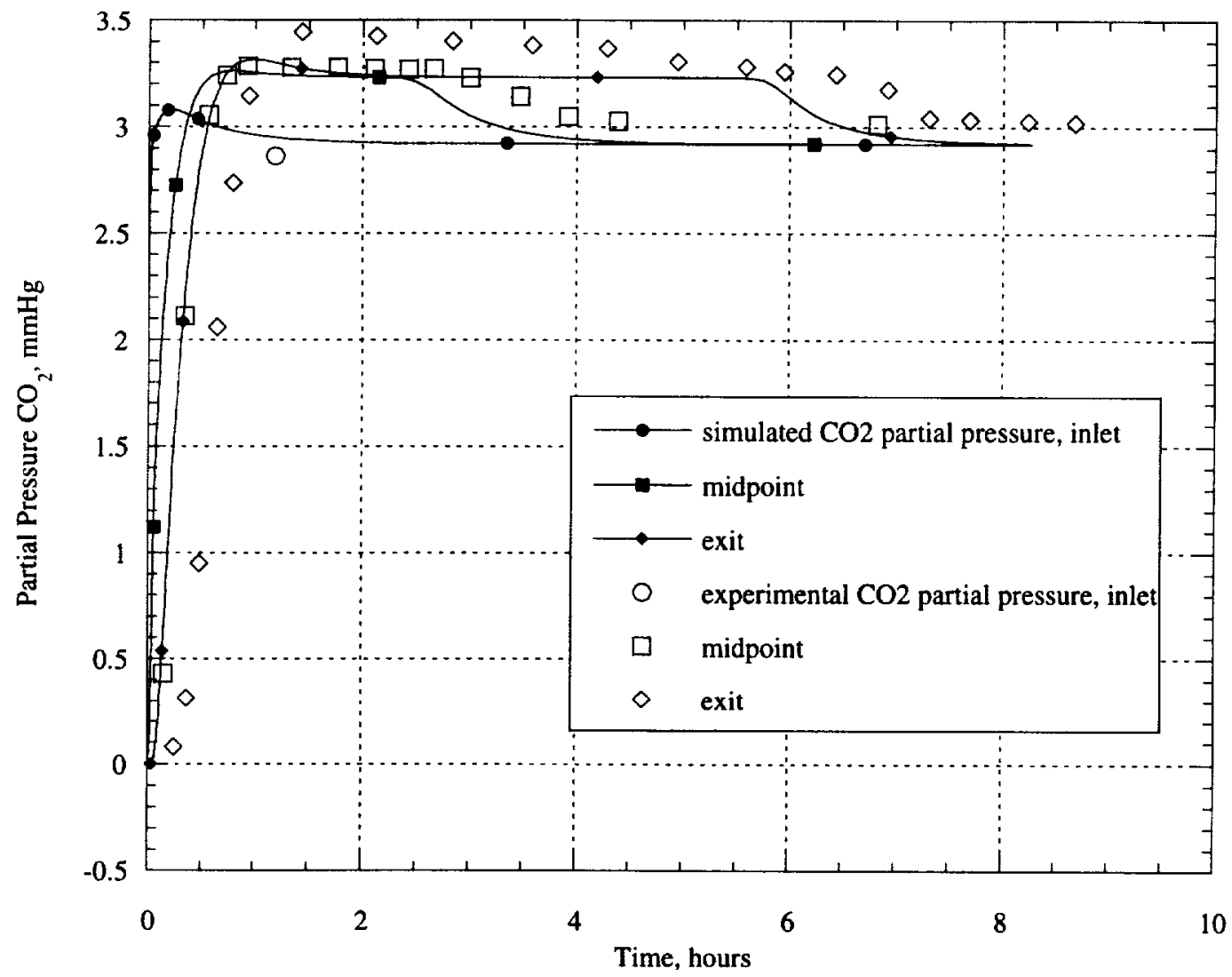

Figure 8: $\mathrm{CO} 2$ breakthrough for $\mathrm{CO} 2 / \mathrm{H} 2 \mathrm{O} / \mathrm{N} 2$ Coadsorption 


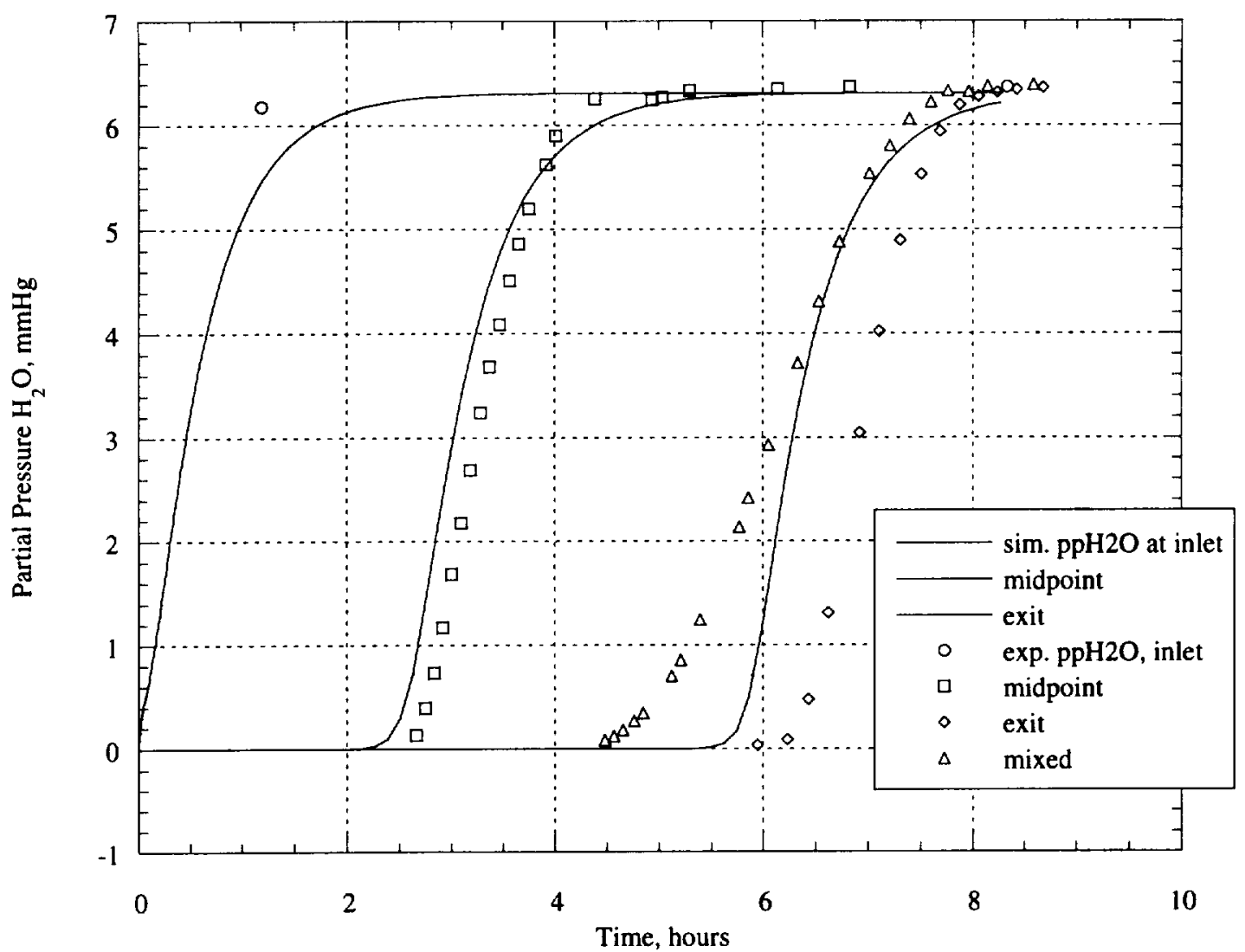

Figure 9: $\mathrm{H} 2 \mathrm{O}$ breakthrough for $\mathrm{CO} / \mathrm{H} 2 \mathrm{O} / \mathrm{N} 2$ Coadsorption 


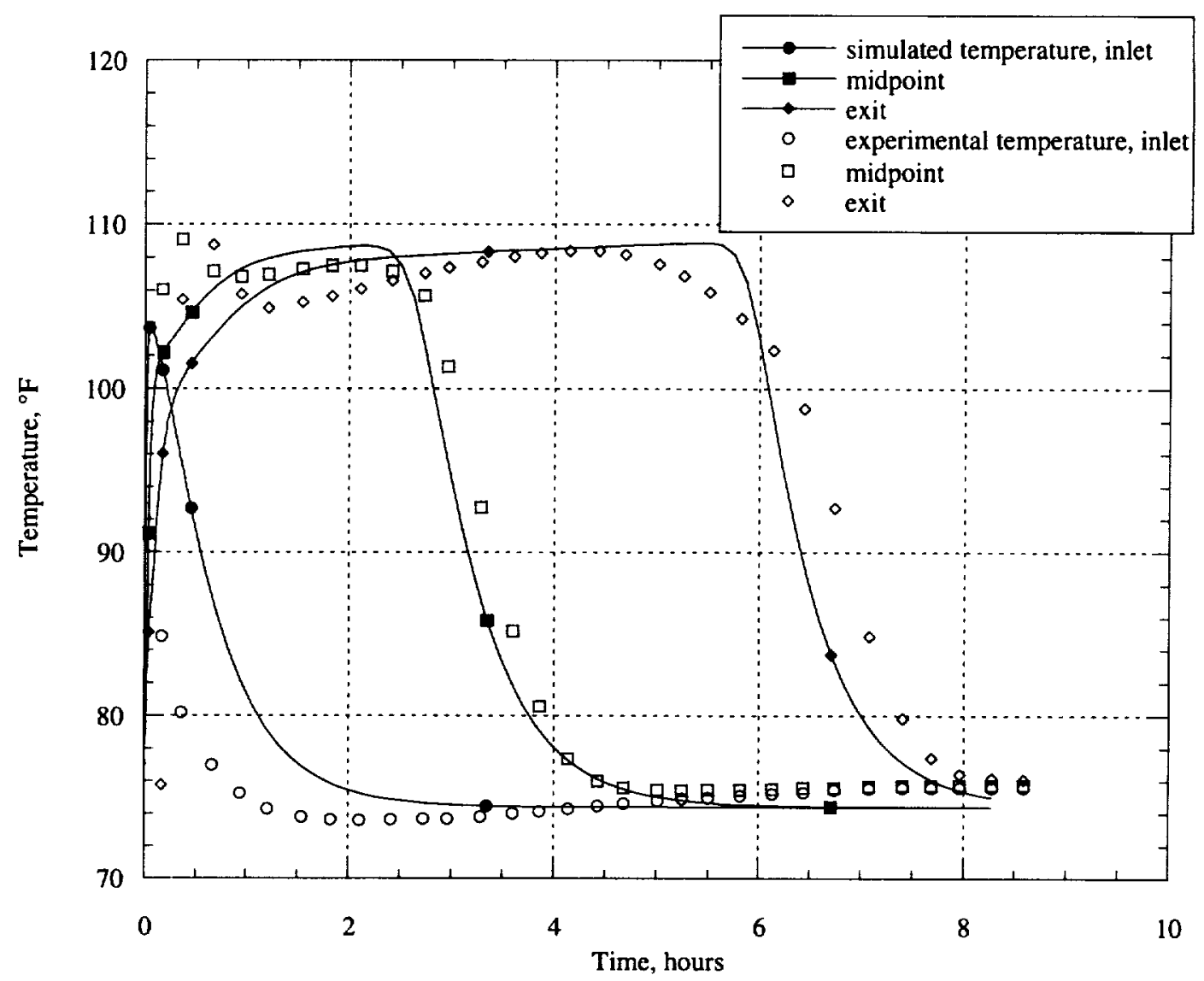

Figure 10: Heat Transfer for $\mathrm{CO} 2 / \mathrm{H} 2 \mathrm{O} / \mathrm{N} 2$ Coadsorption 


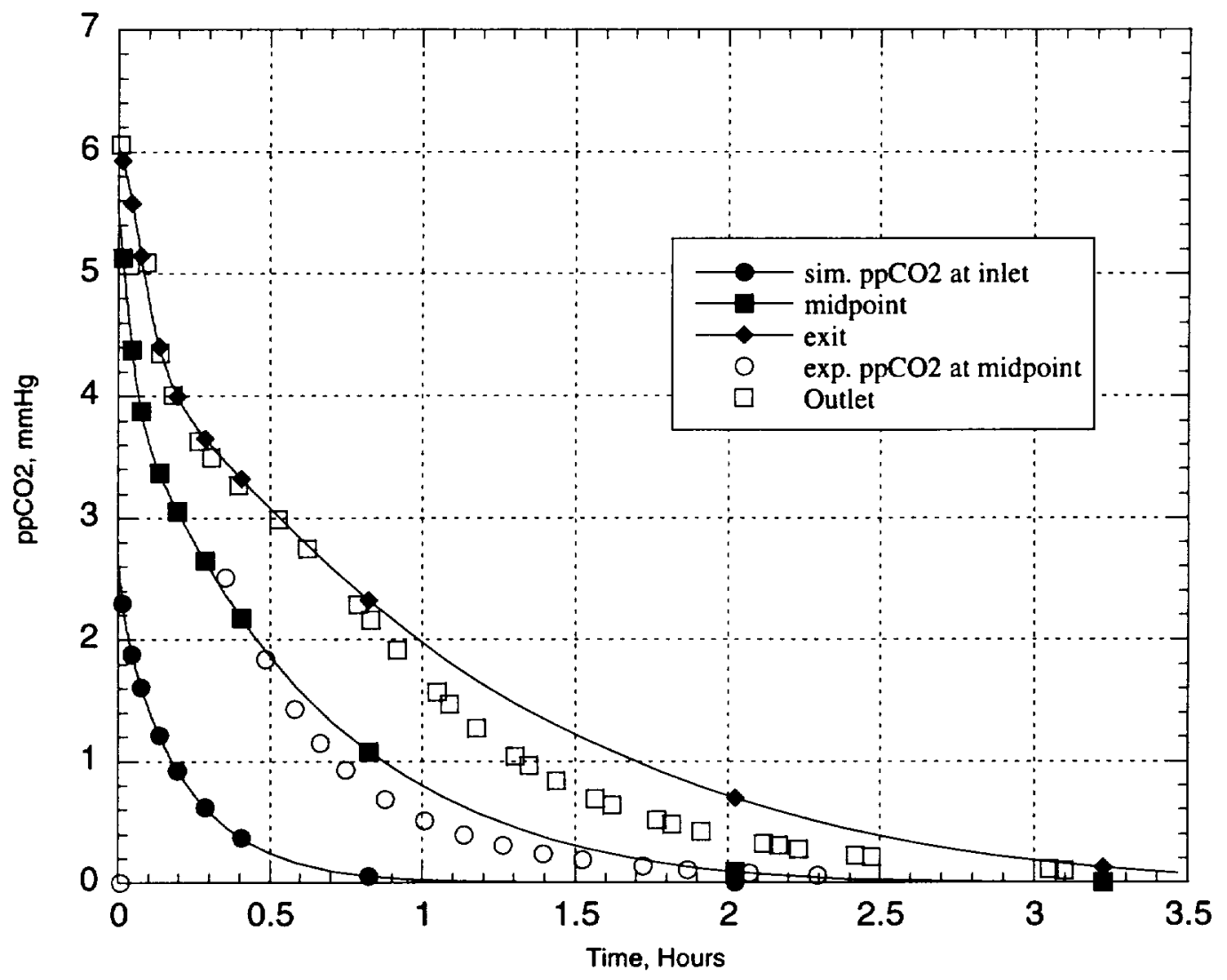

Figure 11: $\mathrm{CO} 2$ Depletion for $\mathrm{CO} 2 / \mathrm{N} 2$ desorption 


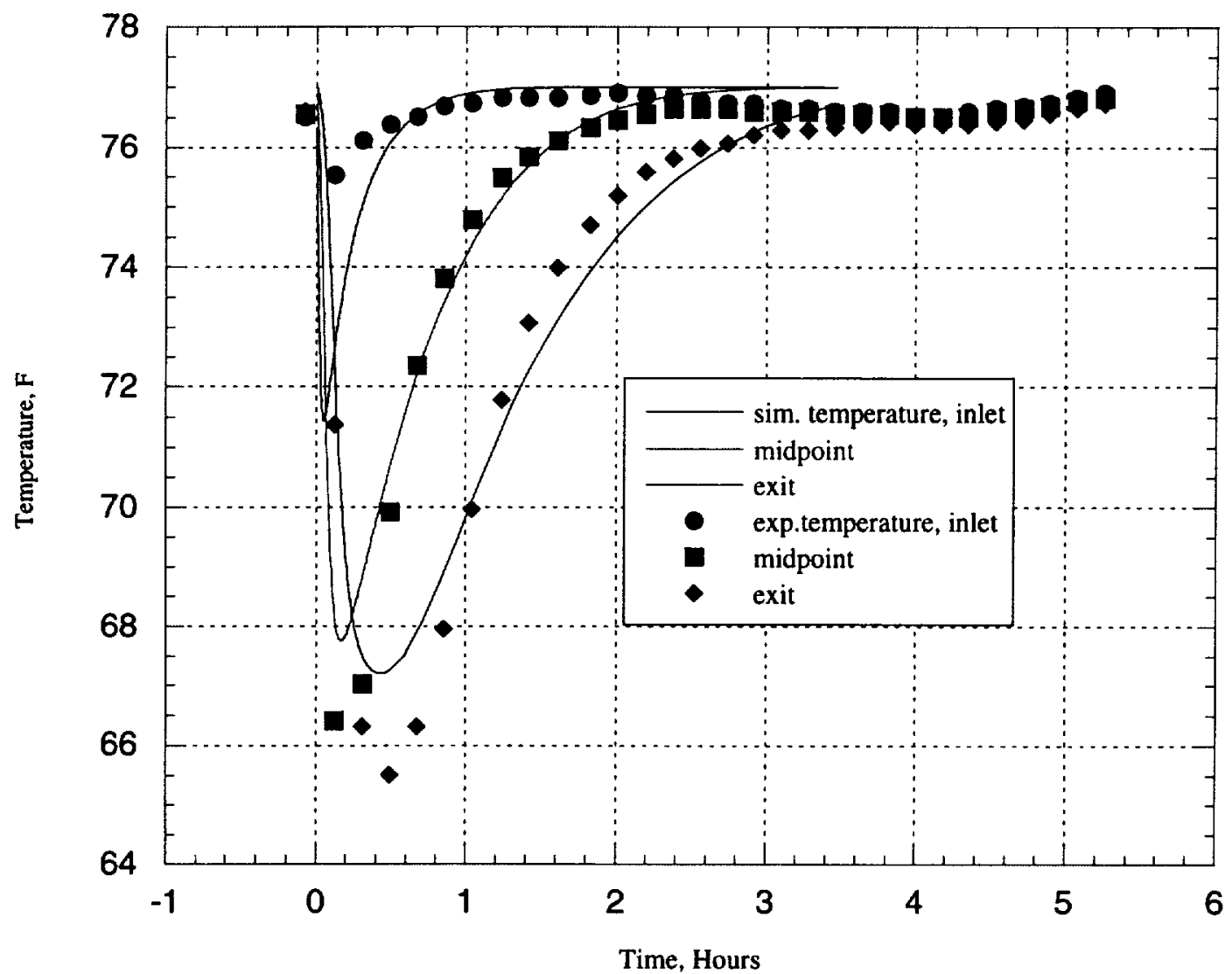

Figure 12: Heat Transfer Effects of $\mathrm{CO} 2$ depletion for $\mathrm{CO} 2 \mathrm{~N} 2$ desorption 


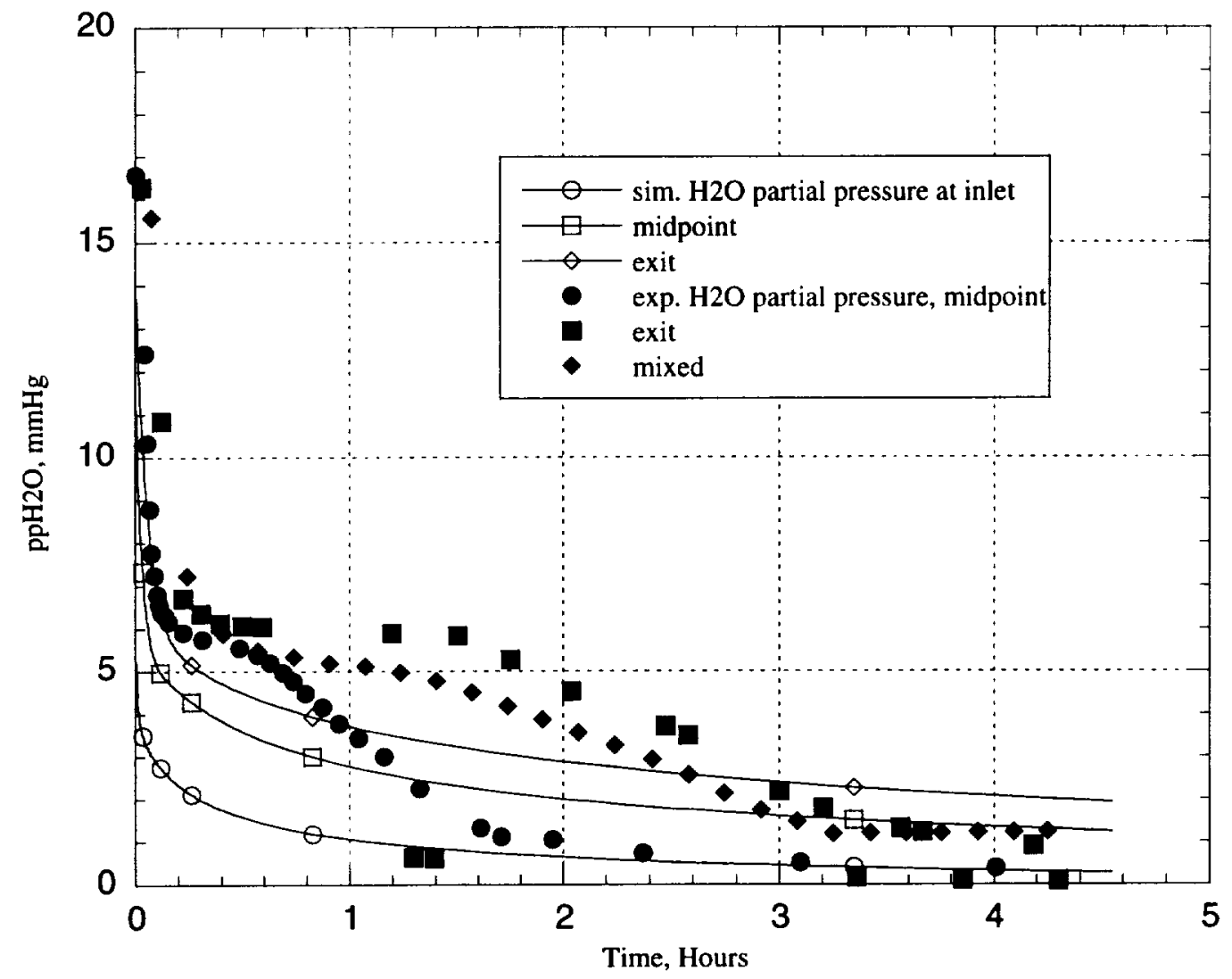

Figure 13: $\mathrm{H} 2 \mathrm{O}$ Depletion for $\mathrm{H} 2 \mathrm{O} / \mathrm{N} 2$ desorption 


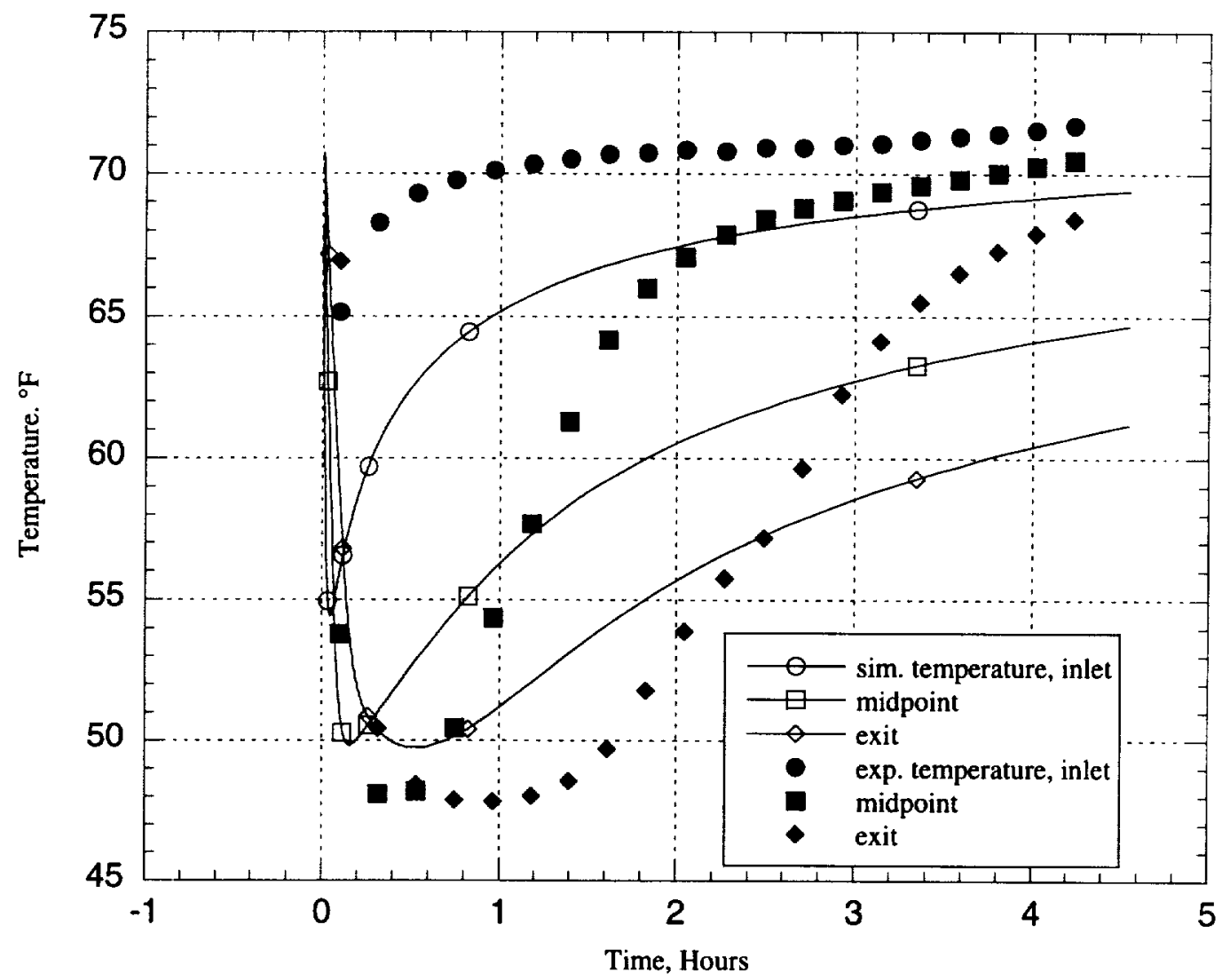

Figure 14: Heat Transfer Effects of H2Odepletion for $\mathrm{H} 2 \mathrm{O} / \mathrm{N} 2$ desorption 